\title{
Article \\ Investigations of Fused Deposition Modeling for Perovskite Active Solar Cells
}

\author{
Leland Weiss *(D) and Tyler Sonsalla
}

Citation: Weiss, L.; Sonsalla, T. Investigations of Fused Deposition Modeling for Perovskite Active Solar Cells. Polymers 2022, 14, 317. https:// doi.org/10.3390/polym14020317

Academic Editor: Bożena Jarząbek

Received: 12 November 2021

Accepted: 5 January 2022

Published: 13 January 2022

Publisher's Note: MDPI stays neutral with regard to jurisdictional claims in published maps and institutional affiliations.

Copyright: (C) 2022 by the authors. Licensee MDPI, Basel, Switzerland. This article is an open access article distributed under the terms and conditions of the Creative Commons Attribution (CC BY) license (https:// creativecommons.org/licenses/by/ $4.0 /$ )
Institute for Micromanufacturing, College of Engineering and Science, Louisiana Tech University Ruston, Ruston, LA 71272, USA; tjs041@latech.edu

* Correspondence: lweiss@latech.edu

\begin{abstract}
The advent of Fused Deposition Modeling (FDM; or 3D printing) has significantly changed the way many products are designed and built. It has even opened opportunities to fabricate new products on-site and on-demand. In addition, parallel efforts that introduce new materials into the FDM process have seen great advances as well. New additives have been demonstrably utilized to achieve thermal, electrical, and structural property improvements. This combination of fabrication flexibility and material additives make FDM an ideal candidate for investigation of perovskite materials in new solar cell efforts. In this work, we fabricate and characterize a perovskite-based solar cell polymer designed for the FDM fabrication processes. Perovskite solar cells have garnered major research interest since their discovery in 2009. Perovskites, specifically methylammonium lead iodide, offer beneficial properties to solar cell fabrication such as long minority charge carrier distance, high light absorption, and simple fabrication methods. Despite the great potential of these materials, however, stability remains an issue in solar cell utilization as the material degrades under ultraviolet light, exposure to oxygen and water, as well as increased temperatures. To mitigate degradation, different fabrication methods have been utilized. Additionally, multiple groups have utilized encapsulation methods post-fabrication and in situ solution processed integration of polymer materials into the solar cell to prevent degradation. In this paper, we leverage the unique ability of FDM to encapsulate perovskite materials and yield a $\mathrm{MAPbI}_{3}-\mathrm{PCL}$ solar material as the active layer for solar cell use. In this manner, increased ability to resist UV light degradation and material stability from other environmental factors can be achieved. This study provides characterization of the material via multiple techniques like SEM (Scanning Electron Microscopy) and XRD (Xray Diffraction) as well as absorbance, transmittance, and photocurrent response. Investigations of processing on perovskite degradation as well as initial solar simulated response are recorded. Unique aspects of the resulting material and process are noted including improved performance with increased operating temperature. Increased electron-hole pair generation is observed for $200 \mu \mathrm{m}$ FDM-printed PCL film, achieving a $45 \%$ reduction in resistance under peak incident flux of $590 \mathrm{~W} / \mathrm{m}^{2}$ with the addition of $\mathrm{MAPbl}_{3}$. This work establishes insight into the use of FDM for full solar cell fabrication and points to the next steps of research and development in this growing field.
\end{abstract}

Keywords: micro; perovskite; solar cell; 3D printing; fused deposition modeling

\section{Introduction}

Over the course of the past decade, significant changes have occurred in the field of electricity production [1]. Specifically, while the use of traditional fuel sources like coal have diminished, there continues to be a rise in the use of so-called "green" energy sources like solar and wind. It is projected that a continued move from traditional, fossil fuel-based energy sources to renewable sources will continue in the decades ahead. Solar energy power production is poised to be increasingly important among the renewable energy sources between now and 2050 [1]. To support new growth in solar energy production, new methods and materials are needed. Fortunately, there have also been significant advances 
in unique materials and new methods of manufacture. Fused Deposition Modeling (FDM), or $3 \mathrm{D}$ printing, is one such advance.

Given this growing interest in solar-based energy and expanding capabilities of FDM, we investigate new FDM processes and materials that allow the fabrication of 3D printed solar cell active layers. There is inherent promise in the approach given that FDM-based devices are no longer constrained to planar type structures, but may be designed and fabricated for unique spaces, shapes and applications well beyond traditional manufacturing constraints. As an example, a curved-radius active layer will provide improved incidence angles with solar input as the day progresses and the sun moves across the sky. FDM also allows future devices to be fabricated on-site and on-demand in situations where traditional shipping of completed devices is more difficult. This could have significant application in non-terrestrial settings [2,3].

Perovskite solar cells, first discovered in 2009, have quickly achieved efficiencies of over $20 \%$ utilizing simple solution-based fabrication methods [4], potentially providing a cost-effective alternative to traditional solar cell technologies. However, perovskite solar cells have also shown stability issues when exposed to ambient atmosphere. It has been shown that UV light, continuous light, oxygen, water, and temperature can affect the stability of perovskite solar cells [5-7]. For these reasons, various methods have been utilized during fabrication and post-fabrication to prolong stability. For example, the use of various epoxies and desiccant have been popular methods in post-fabrication [8-10]. However, these methods increase the fabrication complexity which ultimately effects scalability to commercial application. Other groups have utilized different chemical pathways (i.e., antisolvents, etc.) to extend the stability and fabricate perovskite solar cells in high humidity environments [11-13]. Other efforts have used different electron and hole transport layer combinations to extend the stability of perovskite solar cells in ambient conditions $[4,14]$. However, commonly utilized electron and hole transport materials can be cost prohibitive for larger scale application ( $>\$ 300$ per gram).

In this current effort, the general approach employed to achieve these unique devices encapsulates perovskite materials for extrusion as polymer-composite filaments through a heated nozzle in a layer-by-layer FDM process. This builds on our prior work and allows the incorporation and utilization of various polymer-based materials with unique, entrained additives [15].

Over the past several years, multiple investigations have undertaken the general challenge of three-dimensionally printed perovskite materials. Beyond the general advantages of FDM noted previously, there are several perovskite-specific advantages to this approach. First, FDM processes utilizing composite filaments have been previously demonstrated to align filler particles upon printing [15]. This improves thermal and electrical properties, which in the context of a solar cell can improve charge extraction and performance. Second, the FDM process integrates a polymer barrier around filler particles, which can protect the particles from ambient conditions (i.e., oxygen and water). In this manner, the long-term stability issues related to perovskite solar cells can be naturally addressed via the fabrication process itself.

Many of the FDM-oriented approaches have focused on uses like photoelectric sensing [16] or light production [17-19]. Zhao et al. advanced the general formation of perovskite crystals from disordered to ordered via electric field, producing a more orderly crystal deposition for use in a photosensor with high sensitivity, high stability, and good response [16]. Tai et al. investigated several thermoplastic polymers as protective coatings for perovskite materials and incorporated the effort into light-emitting diode (LED) devices with various emission wavelengths. It was further noted that there was fluorescent behavior of some of the printed structures resulting from this effort [17]. Others have focused on photo-luminescent materials as structural materials [18]. Qaid et al. have investigated the opportunity for light amplification via the alternate $\mathrm{CsPbBr}_{3}$ perovskite material while encapsulating in PMMA polymers [20]. 
In this work, we fabricate and evaluate $\mathrm{MAPbI}_{3}$ perovskite material, suitable for FDM printing application and end use as the photo-active layer in solar cell constructions. Fabrication that produces the polymer-encapsulated printable material and full characterization is presented, followed by initial testing of photocurrent operational results in a 3D-printed test piece. This effort sets the foundation for efforts that incorporate the material into a fully realized solar cell.

\section{Experimental Methods}

To achieve a prototype FDM perovskite active layer, processing, characterization, and printing of the required materials was needed. Material was characterized via several processes including SEM (Scanning Electron Microscopy), XRD (X-ray Diffraction), and photocurrent analysis. This section reviews the fabrication processing as well as the test and characterization steps for the fabricated structures and test pieces.

\subsection{Materials and Fabrication}

\subsubsection{Perovskite Material Fabrication}

This section reviews the material fabrication steps necessary for the creation of the encapsulated perovskite solar material, ready for application as an FDM material. The fabrication of perovskite microcrystals was accomplished utilizing a previously published procedure by Johansson et al. [12]. Methylammonium iodide (MAI) was mixed in isopropyl alcohol until the crystals were completely dissolved. After the crystals were dissolved, lead iodide $\left(\mathrm{PbI}_{2}\right)$ was added in at a 1:1 molar ratio. The resulting solution had a concentration of $0.69 \mathrm{M}$. After addition of $\mathrm{PbI}_{2}$, the solution transparency changed from clear to black signifying the formation of $\mathrm{MAPbI}_{3}$.

After formation of the perovskite, $1 \mathrm{wt}$ \% of 3-(2-aminoethylamino) propy-ldimethoxymethylsilane (i.e., coupling agent (LICA-38)) was added and allowed to stir for 5 min before the addition of polycaprolactone (PCL). PCL was selected as it has a low melting temperature of about $60{ }^{\circ} \mathrm{C}$ and performs well as a water/oxygen barrier [21-23]. The coupling agent was utilized in order to create a voidless interface between the PCL and $\mathrm{MAPbI}_{3}$ crystals. The agent did not degrade the perovskite during preliminary lab testing. Additionally, the printability of filaments was increased with the addition of coupling agent.

PCL was added to the mixture to create a $50 \mathrm{wt} \% \mathrm{MAPbI}_{3}-\mathrm{PCL}$ mixture. A $50 \mathrm{wt} \%$ concentration of $\mathrm{MAPbI}_{3}$ was selected as it allowed the filament to contain the maximum amount of perovskite particles, while still providing the filament with the ability to be extruded/printed at low temperatures $\left(<100{ }^{\circ} \mathrm{C}\right)$ which prevented degradation. The components were stirred for another $5 \mathrm{~min}$ before the solution was added to a recovery flask and IPA was removed from the mixture via rotary evaporator. Figure 1 graphically shows the process.

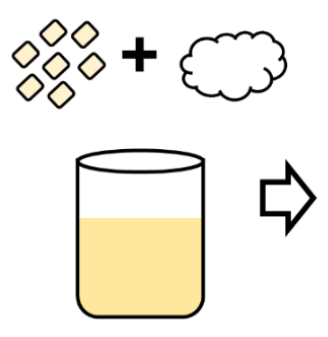

(a)

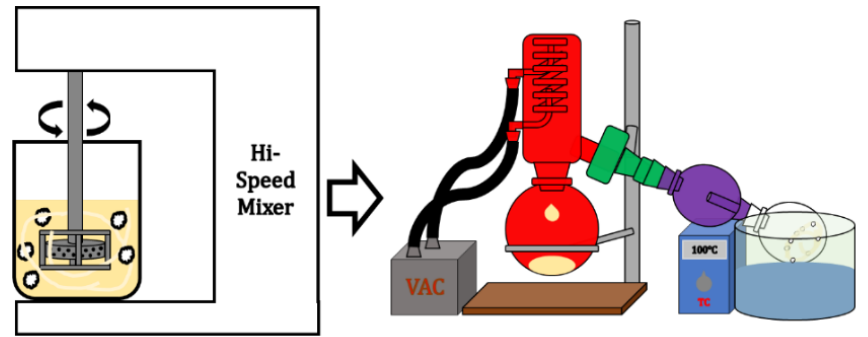

(c)

Figure 1. Perovskite composite fabrication process: (a) Combining PCL and $\mathrm{MAPbI}_{3}-\mathrm{PCL}$ mixture. (b) High-speed mixing. (c) Rotary evaporator use to remove IPA.

Following evaporation, the $\mathrm{MAPbI}_{3}-\mathrm{PCL}$ mixture was placed in a Heraeus Instruments Vacutherm oven equipped with a Fisher Scientific Maxima C vacuum pump (delivering 
pressure less than $1 \times 10^{-4}$ mbar) and dried overnight under light vacuum at $19.1{ }^{\circ} \mathrm{C}$. The resulting $\mathrm{MAPbI}_{3}-\mathrm{PCL}$ powder was extruded into a filament using a Filabot EX2. The temperature of the extruder was set between 70 and $80^{\circ} \mathrm{C}$. The final resulting filament was optically black in color with a slight shine. Temperatures above this range would result in a yellow filament indicating degradation of the perovskite crystals.

\subsubsection{FDM Perovskite Thin Film Fabrication}

A fused deposition modeling system (Lulzbot Mini, Lulzbot Taz 5, or Ultimaker 3) controlled by Cura was used to fabricate all plain and composite filament materials characterized in this work. The nozzle diameter utilized was $2.0 \mathrm{~mm}$. The software was programmed to print a thin-film with thickness measured via digital micrometer after printing. The test pieces were designed in Solidworks and imported into the Cura software as .STL files. The thicknesses tested were $25 \mu \mathrm{m}, 50 \mu \mathrm{m}, 100 \mu \mathrm{m}$ and $200 \mu \mathrm{m}$. Overall length and width of these thin-film samples was $25 \mathrm{~mm}$ by $25 \mathrm{~mm}$. A Nikon Digimicro was used to determine the thickness of the FDM printed thin films.

\subsubsection{FDM Perovskite Photoconductivity Test Piece}

Following thin film preparation and evaluation, the $\mathrm{MAPbI}_{3}-\mathrm{PCL}$ composite was printed via FDM into a disk to allow initial investigation of photoconductivity as well as larger-scale 3D printer capability with the new material. The photoconductivity test piece had a diameter of $25 \mathrm{~mm}$ and thickness of $0.9 \mathrm{~mm}$. Two circular holes with a diameter of $3 \mathrm{~mm}$, separated by $12.5 \mathrm{~mm}$ were printed into the structure as electrode attachment points. Printing was accomplished via commercially available FDM printers. Twin throughbolts were utilized as electrodes and attached to the photoconductivity test piece via MG Chemicals Silver Conductive Epoxy to ensure electrical connection. Figure 2 shows the fabricated test piece and design.

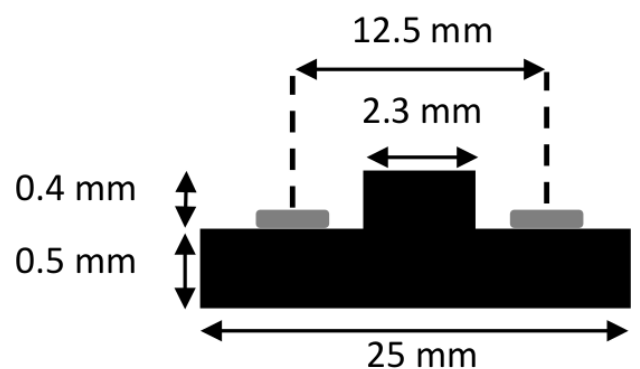

(a)

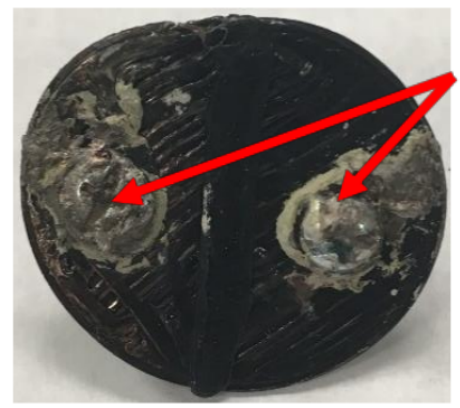

(b)

Figure 2. (a) Layout of photoconductivity sample. (b) Photoconductivity sample and electrode attachment points (red arrow).

\subsection{Test Setup}

Tests were conducted that included characterization of the fabricated perovskite materials as well as photoconductivity and other operationally-oriented tests. Test setups and characterization procedures are discussed in this section.

\subsubsection{Material Characterization Testing}

Material characterization of the FDM perovskite material included the use of SEM, UV-Vis (Ultraviolet-visible Spectroscopy), and XRD prior to any material operational characterization. A Hitachi S4800 FE-SEM (Hitachi City: White Plains, NY, USA) was utilized to image the $\mathrm{MAPbI}_{3}$ crystals, $\mathrm{MAPbI}_{3}$ crystals after coupling agent treatment, and $\mathrm{MAPbI}_{3}-\mathrm{PCL}$ composite film after FDM printing. Specific attention was paid to potential damage caused by the FDM print process as well as action of the coupling agent in the final material. 
To more completely establish the successful formation of $\mathrm{MAPbI}_{3}$ microcrystals, a Bruker D8 X-ray diffractometer XRD) (Bruker City: Madison, WI, USA) was utilized. This allowed insight into the crystal structure of the perovskite crystals and the printed photoconductivity test pieces (thin films) of $\mathrm{MAPbI}_{3}-\mathrm{PCL}$. For clarity, XRD spectrum of $\mathrm{PbI}_{2}$ powder, $\mathrm{MAI}$ powder, $\mathrm{MAPbI}_{3}$ powder and $\mathrm{PCL}-\mathrm{MAPBI}_{3}$ thin film was examined and compared against characteristic peaks associated with $\mathrm{MAPbI}_{3}$, and $\mathrm{MAPBI}-\mathrm{PCL}$ to validate integration and processing into the desired perovskite filament.

\subsubsection{Absorbance and Transmittance/Reflectance Testing of PCL Thin Films}

A Jasco V-530 UV-Vis spectrophotometer (Jasco Inc., Easton, MD, USA) was utilized to characterize the absorbance spectrum of PCL and $\mathrm{MAPbI}_{3}-\mathrm{PCL}$ thin-films. For PCL and $\mathrm{MAPBI}_{3}-\mathrm{PCL}$ the thin films, absorbance was monitored across a range of about 400-1050 nm. The range was selected based on prior work in the field that indicated $\mathrm{MAPBl}_{3}$ absorbance peaking in this range [24-26]. This was done for each thin film sample, with particular attention to the effects of perovskite and its addition into the test materials.

Transmittance spectrum was also investigated. A Filmetrics RT-10 refractometer (Filmetrics, Roselle, CA USA) was utilized to determine the transmittance and reflectance characteristics of the various FDM printed thin-films. The fabricated thin-film pieces (25 $\mu \mathrm{m}, 50 \mu \mathrm{m}, 100 \mu \mathrm{m}$, and $200 \mu \mathrm{m}$ thick) were investigated to assess transmittance through polycaprolactone as well as transmittance vs. thickness levels and light allowance into active layers.

Based on those tests, $200 \mu \mathrm{m}$ film was tested further including tests at room temperature and after heating $\left(40^{\circ} \mathrm{C}, 5 \mathrm{~min}\right)$ to monitor performance changes. In addition, tests were also conducted on $\mathrm{PCL}, \mathrm{MAPbI}_{3}-\mathrm{PCL}$, and samples of $\mathrm{MAPbI}_{3}-\mathrm{PCL}-\mathrm{LICA} 38$ (coupling agent).

\subsubsection{I-V Sweep and Photocurrent Testing}

Using the FDM perovskite test pieces constructed for the purpose, electrodes were attached via wire to a Keithley 2400 Sourcemeter(Keithley/Tektronix, Beaverton, OR, USA). Current-voltage (I-V) sweeps from $-10 \mathrm{~V}$ to $10 \mathrm{~V}$ by $0.1 \mathrm{~V}$ were performed to determine current increase once the material was exposed to light. Dark conditions were also tested in order to provide conclusive results indicating the material reacted to light and not I-V sweep.

All photoconductivity tests were conducted at room temperature. The outcome of these tests was compared to validate perovskite absorption ranges based on prior work in the field [24-26]. The light was applied with a Spectra-Physics 66900 solar simulator (Newport/Spectra-Physics, Milpitas, CA, USA). Input power was varied from 50-80 W, which corresponded to an incident flux of $252-590 \mathrm{~W} / \mathrm{m}^{2}$. Flux was measured with a Newport 91150V Reference Cell and Meter (Newport, Milpitas, CA, USA). This product followed ISO-17025 standards and the output reading was in sun units (where 1 sun is equal to $1000 \mathrm{~W} / \mathrm{m}^{2}$ at $25^{\circ} \mathrm{C}$ and Air Mass 1.5 Global Reference). This corresponded to approximately half of what could be expected on a sunny, summer day (approximately $1000 \mathrm{~W} / \mathrm{m}^{2}$ ). This provided an adequate but conservative simulated solar input for these tests and investigated how light intensity affected photoconductivity. Incident fluxes at each input power level are summarized in Table 1.

Table 1. Incident flux versus input power.

\begin{tabular}{cc}
\hline Input Power $(\mathbf{W})$ & Incident Flux $\left(\mathbf{W} / \mathbf{m}^{2}\right)$ \\
\hline $50 \mathrm{~W}$ & $252 \mathrm{~W} / \mathrm{m}^{2}$ \\
\hline $60 \mathrm{~W}$ & $364 \mathrm{~W} / \mathrm{m}^{2}$ \\
\hline $70 \mathrm{~W}$ & $459 \mathrm{~W} / \mathrm{m}^{2}$ \\
\hline $80 \mathrm{~W}$ & $590 \mathrm{~W} / \mathrm{m}^{2}$ \\
\hline
\end{tabular}




\section{Results and Discussion}

This section presents the specific results of the various tests that were conducted on both material and full solar cell constructs. Specific material test results are presented first, followed by the solar photo-conductivity test piece performance test results.

\subsection{Material Characterization Test Results}

Figure 3 shows SEM images of perovskite, perovskite treated with coupling agent, FDM printed $\mathrm{MAPbI}_{3}-\mathrm{PCL}$ thin-film, and PCL/perovskite interface. Figure 3a shows the perovskite crystals, which had a cubic structure before coupling agent introduction. The different size of crystals remained following fabrication as well. Figure $3 b$ shows the perovskite crystals after coupling agent introduction. As can be noted in the image, the cubic structure remained, however it was coated with the silane coupling agent used in the study. After printing the $\mathrm{MAPbI}_{3}-\mathrm{PCL}$ thin-film, the surface morphology was rough and had the appearance of embedded cubes as depicted in Figure 3c. The coupling agent aided in creating a voidless interface between the perovskite and PCL shown in Figure $3 \mathrm{~d}$.

This investigation via SEM images showed that coupling agent introduction, filament extrusion, and FDM printing process did not damage the structure of the $\mathrm{MAPbI}_{3}$ crystals. Thus, the FDM filament manufacture and printing process was found to be a viable option to produce $\mathrm{MAPbI}_{3}$ composites.

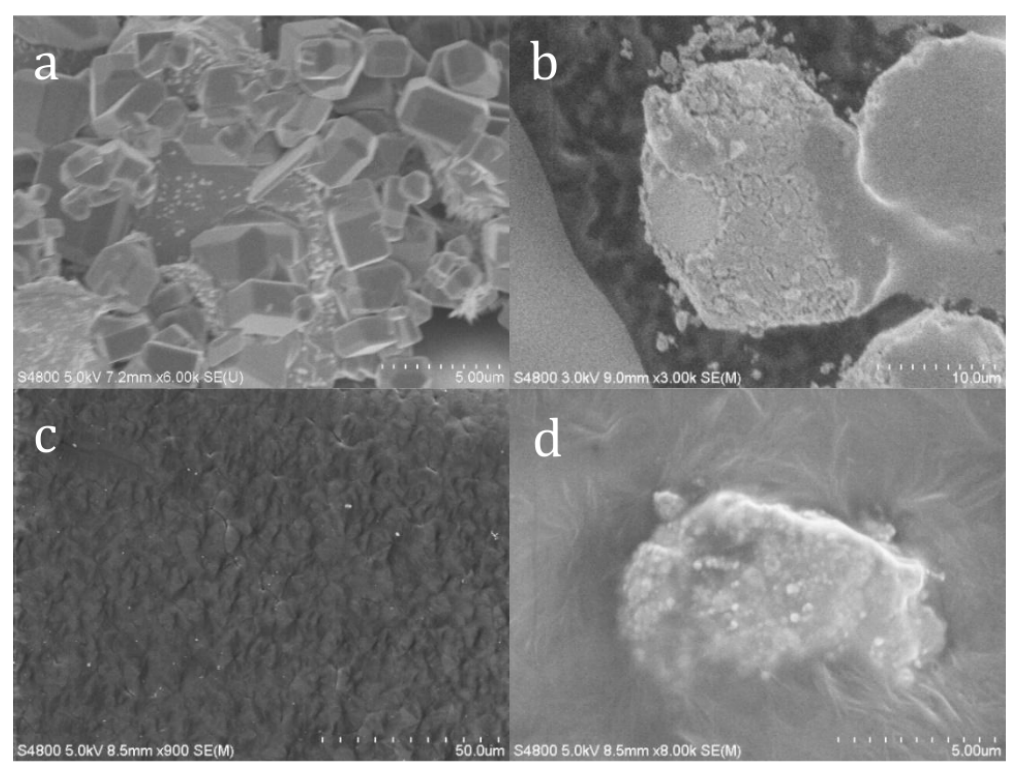

Figure 3. SEM images of (a) perovskite (b) coupling agent treated perovskite (c) PCL-50 wt.\% Perovskite (d) PCL-50 wt.\% Perovskite.

XRD characterization was performed and is presented in Figures 4 and 5. Table 2 summarizes the findings. In general, these findings indicated the successful formation of $\mathrm{MAPbI}_{3}$ microcrystals, integration of the $\mathrm{MAPbI}_{3}$ microcrystals into the PCL matrix, and good stability with lack of degradation during the FDM printing process.

Figure 4 shows XRD spectrum of $\mathrm{PbI}_{2}$ powder, $\mathrm{MAI}$ powder, $\mathrm{MAPbI}_{3}$ powder, and $\mathrm{PCL}_{-} \mathrm{MAPBI}_{3}$ thin film. The diffraction peaks at $2 \Theta=26^{\circ}, 34^{\circ}, 39^{\circ}, 46^{\circ}$ (denoted with $\Delta$ ) correspond to the (101), (102), (110), and (103) lattice planes of $\mathrm{PbI}_{2}$ [27]. Peaks at $2 \Theta=20^{\circ}$ and $30^{\circ}$ (denoted with $\square$ ) correspond to the (002) and (003) lattice planes of MAI [28]. $\mathrm{MAPbI}_{3}$ contained peaks at $2 \Theta=14^{\circ}, 23^{\circ}, 28.3^{\circ}$ and $28.6^{\circ}$ (denoted with $\circ$ ), which corresponded to the (002), (121), (004), and (220) lattice planes [8]. The characteristic peaks associated with $\mathrm{MAPbI}_{3}$ remained in the $\mathrm{PCL}-\mathrm{MAPbI}$ composite. 


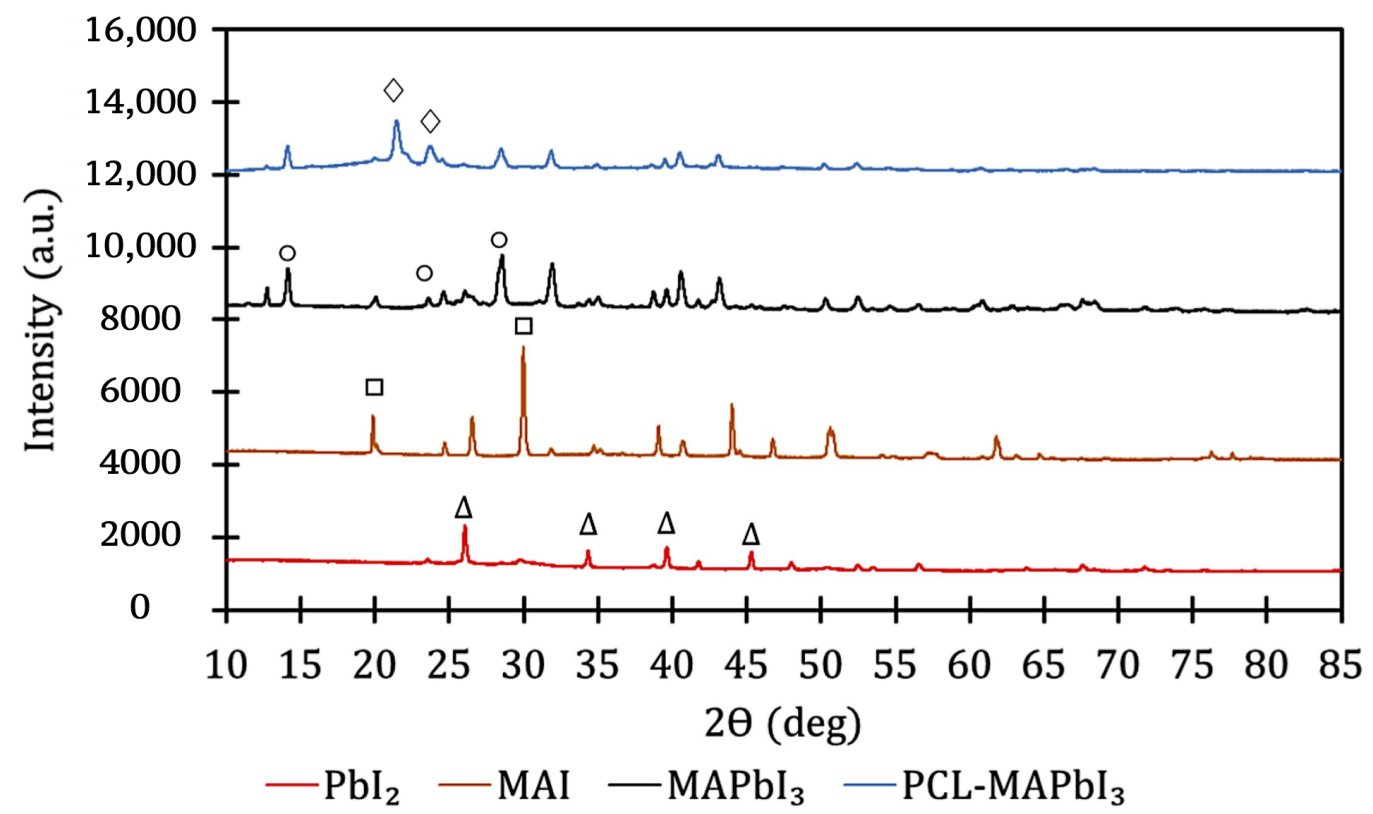

Figure 4. $\mathrm{XRD}$ of $\mathrm{PbI}_{2}, \mathrm{MAI}, \mathrm{MAPbI}_{3}$, and $\mathrm{MAPbI}_{3}-\mathrm{PCL}$.

Figure 5 shows an XRD spectrum of perovskite overlaid on the spectrum for PCL$\mathrm{MAPbI}_{3}$ composite. Although the peak intensities were reduced in the PCL-MAPbI composite, the $\mathrm{MAPbI}_{3}$ peaks show the integration and processing of the $\mathrm{MAPbI}_{3}$ into PCL-MAPbI ${ }_{3}$ filament. The peaks at $2 \Theta=21^{\circ}$ and $23^{\circ}$ (denoted with $*$ in Figure 4 ) peaks corresponded to the (110) and (200) lattice planes of PCL and agree with literature values [29-32].

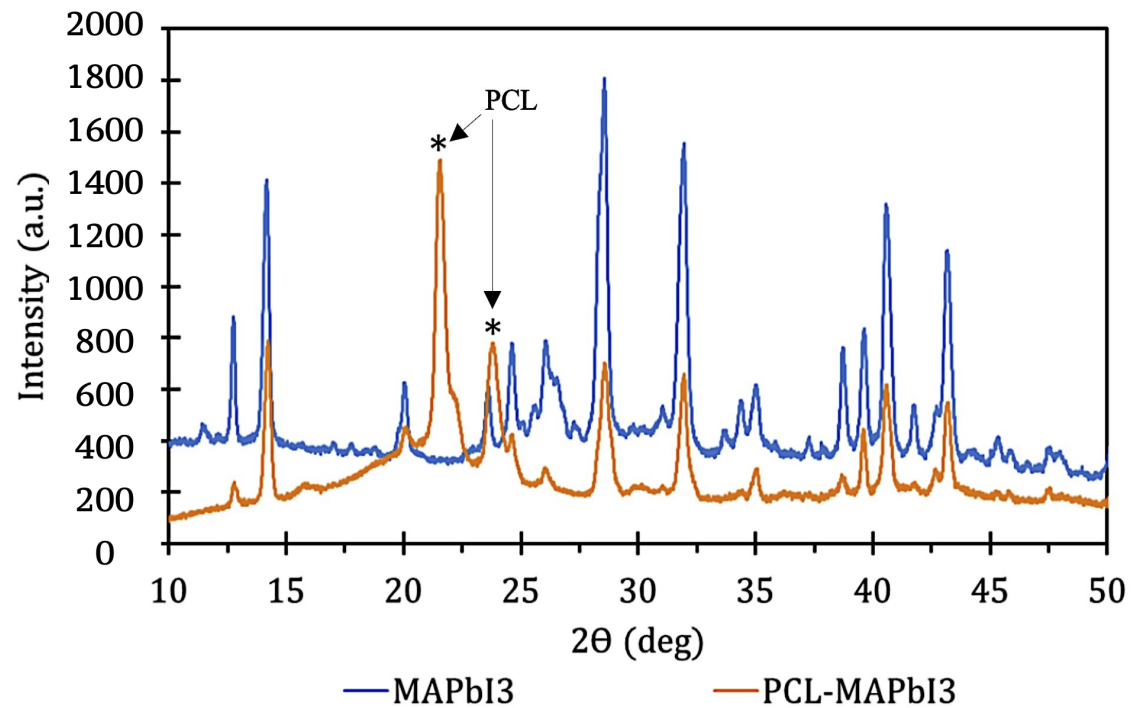

Figure 5. $\mathrm{XRD}$ of $\mathrm{MAPbI}_{3}$ and $\mathrm{PCL}-\mathrm{MAPbI}_{3}$. Note: $*$ indicates PCL corresponding lattice plane peaks.

One key goal of these essential material evaluations was to confirm that the perovskite material itself did not exhibit significant degradation either in the preliminary mixing, or subsequent processing as it was made suitable for FDM utilization as a 'printable' polymer. This was shown through both SEM and XRD analysis where expected perovskite properties were evident throughout. This allowed continued investigation of the polymer in more optically-oriented testing. 
Table 2. Summary of diffraction peaks and lattice planes for $\mathrm{PbI}_{2}, \mathrm{MAI}, \mathrm{MAPbI}_{3}$, and PCL-MAPbI 3 .

\begin{tabular}{|c|c|c|c|}
\hline Material & Diffraction Peak $2 \Theta$ & Lattice Plane (hkl) & Reference \\
\hline Lead Iodide $\left(\mathrm{PbI}_{2}\right)$ & $\begin{array}{l}26^{\circ} \\
34^{\circ} \\
39^{\circ} \\
46^{\circ}\end{array}$ & $\begin{array}{l}(101) \\
(102) \\
(110) \\
(103)\end{array}$ & [27] \\
\hline $\begin{array}{l}\text { Methylammonium } \\
\text { Iodide (MAI) }\end{array}$ & $\begin{array}{l}20^{\circ} \\
30^{\circ}\end{array}$ & $\begin{array}{l}(002) \\
(003)\end{array}$ & [28] \\
\hline $\begin{array}{l}\text { Methylammonium Lead } \\
\text { Triiodide }\left(\mathrm{MAPbI}_{3}\right)\end{array}$ & $\begin{array}{c}14^{\circ} \\
23^{\circ} \\
28.3^{\circ} / 28.6^{\circ}\end{array}$ & $\begin{array}{c}(002) \\
(121) \\
(004) /(220)\end{array}$ & [12] \\
\hline $\begin{array}{c}\text { Polycaprolactone } \\
\text { Methylammonium Lead } \\
\text { Triiodide (PCL-MAPbI }\end{array}$ & $\begin{array}{l}21^{\circ} \\
23^{\circ}\end{array}$ & $\begin{array}{l}(110) \\
(200)\end{array}$ & {$[33,34]$} \\
\hline
\end{tabular}

\subsection{Absorbance and Transmittance Spectrum Results}

With material properties verified, evaluation turned to optical performance and properties. Figure 6 shows the transmittance spectrum for PCL thin films from 400-1050 nm. The thicknesses tested were $25 \mu \mathrm{m}, 50 \mu \mathrm{m}, 100 \mu \mathrm{m}$, and $200 \mu \mathrm{m}$. The $200 \mu \mathrm{m}$ thicknesses were also tested with one or two coatings of Smooth-On XTC-3D. The maximum transmittance occurred in the $25 \mu \mathrm{m}$ sample, which had a transmittance of $29.6 \%$ at $1050 \mathrm{~nm}$. Samples had decreasing transmittance with increasing thickness, the lowest transmittance occurred in the $200 \mu \mathrm{m}$ sample with two coatings of the Smooth-On XTC-3D at $0.9 \%$ and $393 \mathrm{~nm}$. Maximum transmittance did increase from a single coating of Smooth-On XTC-3D on a $200 \mu \mathrm{m}$ PCL sample to $4.1 \%$ when compared to the $200 \mu \mathrm{m}$ plain PCL sample, which attained a maximum transmittance of $1.4 \%$. Transmittance increased for all samples with increasing wavelength except the $200 \mu \mathrm{m}$ sample with a double coating of Smooth-On XTC 3D.

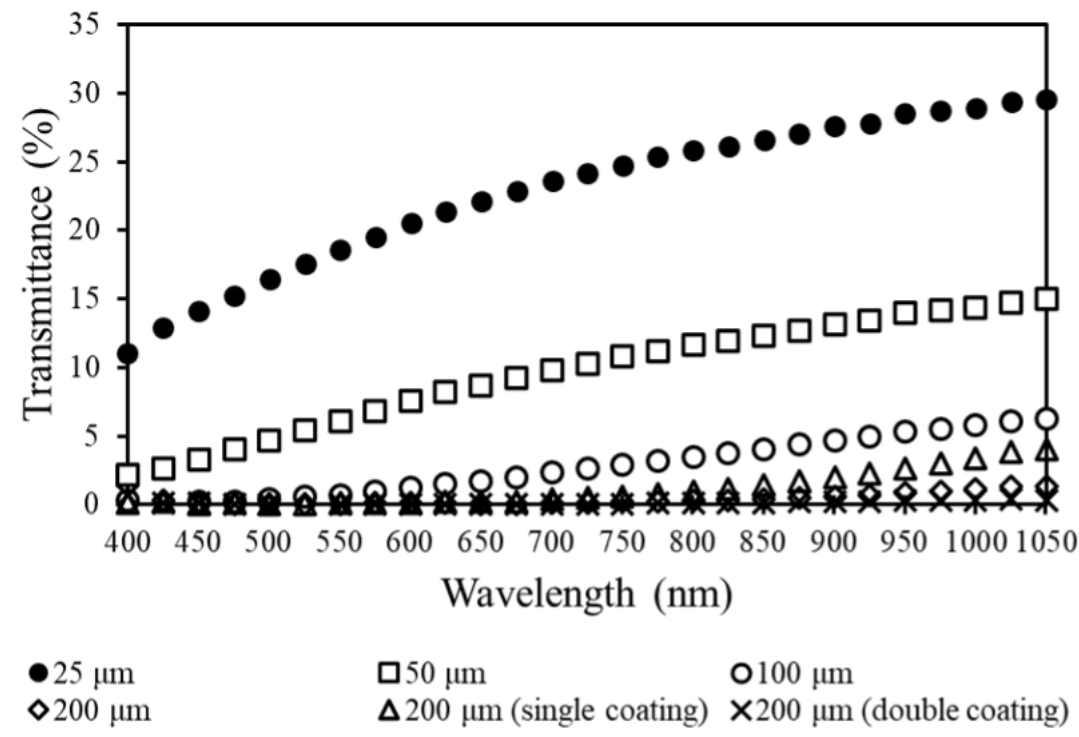

Figure 6. Transmittance spectrums for PCL thin films.

This demonstrated the effect of thickness on optical transparency with thinner FDMprinted samples allowing more light into the active layer in a solar cell structure. However, even at a thickness of $200 \mu \mathrm{m}$ light still entered the active layer. This also confirmed that PCL allowed transmission of optical wavelengths absorbed by $\mathrm{MAPbI}_{3}$ to transmit through the layer. 
The use and performance of the XTC-3D coating is also worth noting. The primary purpose of the coating was to reduce surface roughness, which reduces light scattering effects of the 3D printed film. However, while one layer improved performance, a second layer had negative effects. One obvious reason is that increased layering effectively reduced transmittance simply via thickness, despite the initial benefit of reduced light scatter. Further, the use of a second layer may cause negative light-transmittance reflecting effects. For instance, the second layer of the XTC-3D may produce an XTC-air-XTC interface to form causing light to bounce back and forth. This is an outcome of the tendency of XTC-3D to bond to itself in layering processes. Consequently, this would lead to the longer wavelength range being absent in the transmittance spectrum of the double-coated samples.

Figure 7 shows the transmittance spectrum for $200 \mu \mathrm{m}$ samples of PCL, PCL-MAPbI ${ }_{3}$, and samples of $\mathrm{PCL}-\mathrm{MAPbI}_{3}-\mathrm{LICA} 38$ at room temperature and after heating at $40{ }^{\circ} \mathrm{C}$ for $5 \mathrm{~min}$. Transmittance generally increased for all samples as wavelength increased. Additionally, transmittance increased once the samples were heated except in the case of the PCL-MAPbI$-\mathrm{LICA}_{3}$, which decreased in transmittance after heating. The maximum transmittance occurred in the PCL sample after heating at 30.4\%. The addition of $\mathrm{MAPbI}_{3}$ into PCL reduced the maximum transmittance to $4.9 \%$ after heating the sample. While initially seemingly a negative outcome, this reduction in transmittance could be a good indicator of absorbance due to the presence of $\mathrm{MAPbI}_{3}$ micro/nanocrystals.

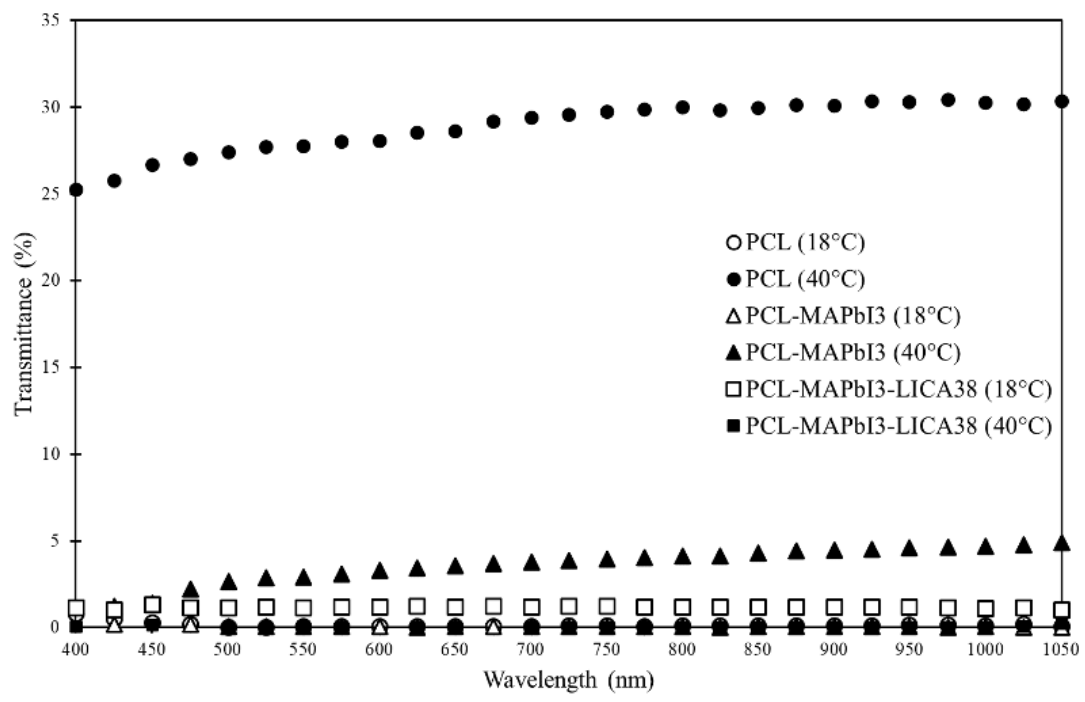

Figure 7. Transmittance spectrum of PCL, PCL-MAPbI 3 , and PCL-MAPbI 3 -LICA38.

Figure 8 shows the UV-Vis absorbance spectrum of a plain PCL thin-film and a $\mathrm{MAPbI}_{3}-\mathrm{PCL}$ thin-film from 350-1000 nm. After the addition of perovskite, the absorbance across all wavelengths was increased. The most prominent increases occurring from 400-800 nm. Given this known absorption range from prior work in the field, this confirmed an active and receptive perovskite material [24-26]. 


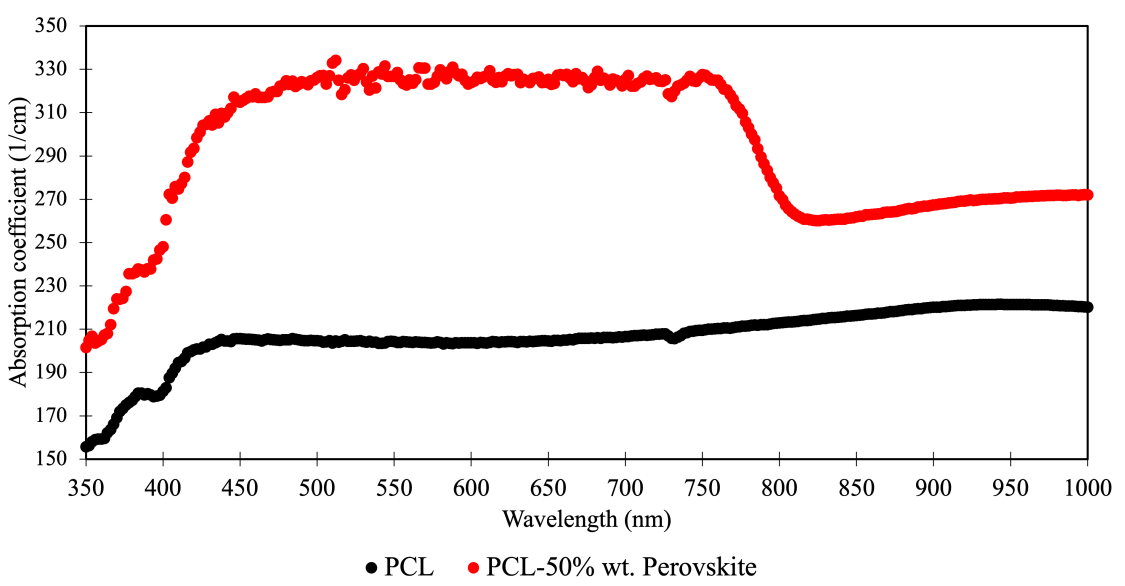

Figure 8. UV-Vis of PCL thin-film and PCL-MAPbI ${ }_{3}$ thin-film.

\subsection{Photocurrent Characterization Results}

Following setup and test procedure described in Section 2, photocurrent characterization tests were completed on the fabricated test piece with attached electrodes. Figure 9 shows I-V curve test result of the photoconductivity of the $\mathrm{MAPbI}_{3}-\mathrm{PCL}$ composite at different power input solar simulator levels. These ranged from 50-80 W. The linear current-voltage curve indicated ohmic contacts were formed at the composite/electrode interfaces. In dark conditions, the resistance was $9.79 \times 10^{9} \mathrm{ohms}$. At $80 \mathrm{~W}$, the resistance was $5.46 \times 10^{9} \mathrm{ohms}$. It is interesting to note that resistance was decreased as lighting intensity was increased (at the same voltage levels). This signified an increase in photocurrent at higher light intensities, which indicated increased electron-hole pair generation. Table 3 further summarizes the results.

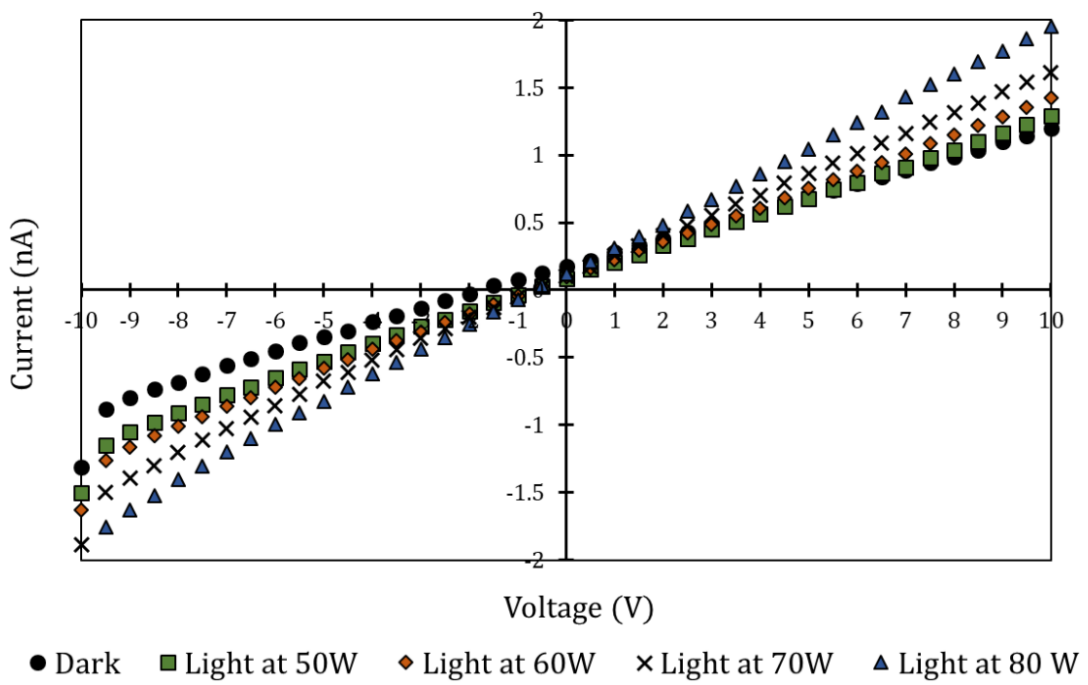

Figure 9. I-V curve of $\mathrm{MAPbI}_{3}-\mathrm{PCL}$ composite in dark, $50 \mathrm{~W}, 60 \mathrm{~W}, 70 \mathrm{~W}$, and $80 \mathrm{~W}$.

Table 3. Resistances of photoconductivity test piece at different power levels.

\begin{tabular}{cc}
\hline Input Power (W) & Resistance (M-ohms) \\
\hline Dark, 0 W & $9.79 \times 10^{3}$ \\
\hline $50 \mathrm{~W}$ & $8.29 \times 10^{3}$ \\
\hline $60 \mathrm{~W}$ & $7.58 \times 10^{3}$ \\
\hline $70 \mathrm{~W}$ & $6.62 \times 10^{3}$ \\
\hline $80 \mathrm{~W}$ & $5.46 \times 10^{3}$ \\
\hline
\end{tabular}


In summary, reaction of the new polymer FDM materials showed the promise of an active solar layer even given the fabrication steps that included FDM extrusion. Photoreaction performance of the material in the thin layer FDM pieces and 3D fabricated photo conductivity test pieces both showed solar absorption capability and electron-hole pair generation. Further, heating the material increased transmission and performance which holds promise for real devices that operate at more elevated temperatures.

\section{Conclusions}

Perovskite solar cells have generated major research interest since their discovery and offer beneficial properties to solar cell fabrication like long minority charge carrier distance, high light absorption, and simple fabrication methods. Despite the potential for these solar cells, however, stability remains an issue due to material degradation in UV light and other common atmospheric elements. This work investigates the potential for fused deposition modeling (FDM), or 3D printing, to produce perovskite solar cells that can address some of these challenges. Many of these are achieved specifically through the encapsulation and printing process of FDM.

Specific steps have been demonstrated to produce the printable polymer material including $\mathrm{MAPbI}_{3}$ microcrystal fabrication in ambient atmosphere, integration of $\mathrm{MAPbI}_{3}$ into a polymer matrix without degradation, and usage of that $\mathrm{MAPbI}_{3}-\mathrm{PCL}$ composite to fabricate a solar active material. Outcome of testing included a noted increasing transparency with increasing temperature and hence, improving conductivity when exposed to simulated solar light. Further, increased electron-hole pair generation was observed for $200 \mu \mathrm{m}$ FDM-printed PCL film, achieving a 45\% reduction in resistance under peak incident flux of $590 \mathrm{~W} / \mathrm{m}^{2}$ with the addition of $\mathrm{MAPbl}_{3}$.

While these tests were conducted at relatively conservative simulated solar loadings, additional testing at higher solar loading is planned for future work alongside construction of a full solar stack. Fused deposition modeling establishes opportunity to integrate aligned conductive fillers into this composite to improve charge extraction and power output via integrated electrodes. This demonstrates the feasibility and potential of FDM in solar cell fabrication.

Author Contributions: Conceptualization, L.W. and T.S.; methodology, L.W. and T.S.; formal analysis, L.W. and T.S.; investigation, T.S.; resources, L.W.; data curation, T.S.; writing-original draft preparation, L.W. and T.S.; writing-review and editing, L.W. and T.S.; supervision, L.W.; project administration, L.W. All authors have read and agreed to the published version of the manuscript.

Funding: This research was funded by NSF EPSCoR CIMM project under cooperative agreement \#OIA-1541079.

Institutional Review Board Statement: Not applicable.

Informed Consent Statement: Not applicable.

Data Availability Statement: Data archived and maintained by authors.

Conflicts of Interest: The authors declare no conflict of interest.

\section{References}

1. EIA. Annual Energy Outlook 2021 with Projections to 2050, Narrative; Technical Report; Energy Information Administration: Washington, DC, USA, 2021.

2. Werkheiser, N. Overview of NASA Initiatives in 3D Printing and Additive Manufacturing; Technical Report M15-4252; NASA: Washington, DC, USA, 2014.

3. Prater, T.; Werkheiser, N.; Ledbetter, F.; Timucin, D.; Wheeler, K.; Snyder, M. 3D Printing in Zero G Technology Demonstration Mission: Complete experimental results and summary of related material modeling efforts. Int. J. Adv. Manuf. Technol. 2019, 101, 391-417. [CrossRef]

4. Arora, N.; Dar, M.I.; Hinderhofer, A.; Pellet, N.; Schreiber, F.; Zakeeruddin, S.M.; Grätzel, M. Perovskite solar cells with CuSCN hole extraction layers yield stabilized efficiencies greater than 20\%. Science 2017, 358, 768-771. [CrossRef]

5. Domanski, K.; Alharbi, E.A.; Hagfeldt, A.; Grätzel, M.; Tress, W. Systematic investigation of the impact of operation conditions on the degradation behaviour of perovskite solar cells. Nat. Energy 2018, 3, 61-67. [CrossRef] 
6. Bryant, D.; Aristidou, N.; Pont, S.; Sanchez-Molina, I.; Chotchunangatchaval, T.; Wheeler, S.; Durrant, J.R.; Haque, S.A. Light and oxygen induced degradation limits the operational stability of methylammonium lead triiodide perovskite solar cells. Energy Environ. Sci. 2016, 9, 1655-1660. [CrossRef]

7. Moiz, S.A.; Alahmadi, A.N.M. Design of Dopant and Lead-Free Novel Perovskite Solar Cell for 16.85 Efficiency. Polymers 2021, 13, 2110. [CrossRef]

8. Dong, Q.; Liu, F.; Wong, M.K.; Tam, H.W.; Djurišić, A.B.; Ng, A.; Surya, C.; Chan, W.K.; Ng, A.M.C. Encapsulation of perovskite solar cells for high humidity conditions. ChemSusChem 2016, 9, 2597-2603. [CrossRef]

9. Han, Y.; Meyer, S.; Dkhissi, Y.; Weber, K.; Pringle, J.M.; Bach, U.; Spiccia, L.; Cheng, Y.B. Degradation observations of encapsulated planar $\mathrm{CH}_{3} \mathrm{NH}_{3} \mathrm{PbI}_{3}$ perovskite solar cells at high temperatures and humidity. J. Mater. Chem. A 2015, 3, 8139-8147. [CrossRef]

10. Bush, K.A.; Palmstrom, A.F.; Zhengshan, J.Y.; Boccard, M.; Cheacharoen, R.; Mailoa, J.P.; McMeekin, D.P.; Hoye, R.L.; Bailie, C.D.; Leijtens, T.; et al. 23.6\%-efficient monolithic perovskite/silicon tandem solar cells with improved stability. Nat. Energy 2017, 2,1-7. [CrossRef]

11. Yang, F.; Kapil, G.; Zhang, P.; Hu, Z.; Kamarudin, M.A.; Ma, T.; Hayase, S. Dependence of acetate-based antisolvents for high humidity fabrication of $\mathrm{CH}_{3} \mathrm{NH}_{3} \mathrm{PbI}_{3}$ perovskite devices in ambient atmosphere. ACS Appl. Mater. Interfaces 2018, 10, 16482-16489. [CrossRef]

12. Johansson, M.B.; Edvinsson, T.; Bitter, S.; Eriksson, A.I.; Johansson, E.M.; Göthelid, M.; Boschloo, G. From quantum dots to micro crystals: Organolead triiodide perovskite crystal growth from isopropanol solution. ECS J. Solid State Sci. Technol. 2016, 5, P614. [CrossRef]

13. Li, M.; Yan, X.; Kang, Z.; Liao, X.; Li, Y.; Zheng, X.; Lin, P.; Meng, J.; Zhang, Y. Enhanced efficiency and stability of perovskite solar cells via anti-solvent treatment in two-step deposition method. ACS Appl. Mater. Interfaces 2017, 9, 7224-7231. [CrossRef]

14. You, J.; Meng, L.; Song, T.B.; Guo, T.F.; Yang, Y.M.; Chang, W.H.; Hong, Z.; Chen, H.; Zhou, H.; Chen, Q.; et al. Improved air stability of perovskite solar cells via solution-processed metal oxide transport layers. Nat. Nanotechnol. 2016, 11, 75-81. [CrossRef]

15. Sonsalla, T.; Moore, A.; Radadia, A.; Weiss, L. Printer orientation effects and performance of novel 3-D printable acrylonitrile butadiene styrene (ABS) composite filaments for thermal enhancement. Polym. Test. 2019, 80, 106125. [CrossRef]

16. Zhao, Z.; Li, Y.; Du, Y.; Zhang, L.; Wei, J.; Lin, F. Preparation and testing of anisotropic $M A P b I_{3}$ perovskite photoelectric sensors. ACS Appl. Mater. Interfaces 2020, 12, 44248-44255. [CrossRef]

17. Tai, C.L.; Hong, W.L.; Kuo, Y.T.; Chang, C.Y.; Niu, M.C.; Ochathevar, M.K.P.; Hsu, C.L.; Horng, S.F.; Chao, Y.C. Ultrastable, Deformable, and Stretchable Luminescent Organic-Inorganic Perovskite Nanocrystal-Polymer Composites for 3D Printing and White Light-Emitting Diodes. ACS Appl. Mater. Interfaces 2019, 11, 30176-30184. [CrossRef] [PubMed]

18. Zhang, Y.; Zhao, Y.; Wu, D.; Xue, J.; Qiu, Y.; Liao, M.; Pei, Q.; Goorsky, M.S.; He, X. Homogeneous freestanding luminescent perovskite organogel with superior water stability. Adv. Mater. 2019, 31, 1902928. [CrossRef] [PubMed]

19. Chen, M.; Yang, J.; Wang, Z.; Xu, Z.; Lee, H.; Lee, H.; Zhou, Z.; Feng, S.P.; Lee, S.; Pyo, J.; et al. 3D nanoprinting of perovskites. Adv. Mater. 2019, 31, 1904073. [CrossRef]

20. Qaid, S.M.H.; Ghaithan, H.M.; AlHarbi, K.K.; Al-Asbahi, B.A.; Aldwayyan, A.S. Enhancement of Light Amplification of CsPbBr 3 Perovskite Quantum Dot Films via Surface Encapsulation by PMMA Polymer. Polymers 2021, 13, 2574. [CrossRef]

21. Fiedler, T.; Belova, I.; Murch, G.; Poologasundarampillai, G.; Jones, J.; Roether, J.; Boccaccini, A. A comparative study of oxygen diffusion in tissue engineering scaffolds. J. Mater. Sci. Mater. Med. 2014, 25, 2573-2578. [CrossRef] [PubMed]

22. Cava, D.; Giménez, E.; Gavara, R.; Lagaron, J. Comparative performance and barrier properties of biodegradable thermoplastics and nanobiocomposites versus PET for food packaging applications. J. Plast. Film Sheeting 2006, 22, 265-274. [CrossRef]

23. Sanchez-Garcia, M.; Ocio, M.; Gimenez, E.; Lagaron, J. Novel polycaprolactone nanocomposites containing thymol of interest in antimicrobial film and coating applications. J. Plast. Film Sheeting 2008, 24, 239-251. [CrossRef]

24. Tang, X.; Brandl, M.; May, B.; Levchuk, I.; Hou, Y.; Richter, M.; Chen, H.; Chen, S.; Kahmann, S.; Osvet, A.; et al. Photoinduced degradation of methylammonium lead triiodide perovskite semiconductors. J. Mater. Chem. A 2016, 4, 15896-15903. [CrossRef]

25. Roldán-Carmona, C.; Gratia, P.; Zimmermann, I.; Grancini, G.; Gao, P.; Graetzel, M.; Nazeeruddin, M.K. High efficiency methylammonium lead triiodide perovskite solar cells: The relevance of non-stoichiometric precursors. Energy Environ. Sci. 2015, 8, 3550-3556. [CrossRef]

26. Abdelmageed, G.; Mackeen, C.; Hellier, K.; Jewell, L.; Seymour, L.; Tingwald, M.; Bridges, F.; Zhang, J.Z.; Carter, S. Effect of temperature on light induced degradation in methylammonium lead iodide perovskite thin films and solar cells. Sol. Energy Mater. Sol. Cells 2018, 174, 566-571. [CrossRef]

27. Acuna, D.; Krishnan, B.; Shaji, S.; Sepulveda, S.; Menchaca, J.L. Growth and properties of lead iodide thin films by spin coating. Bull. Mater. Sci. 2016, 39, 1453-1460. [CrossRef]

28. Song, Z.; Watthage, S.C.; Phillips, A.B.; Tompkins, B.L.; Ellingson, R.J.; Heben, M.J. Impact of processing temperature and composition on the formation of methylammonium lead iodide perovskites. Chem. Mater. 2015, 27, 4612-4619. [CrossRef]

29. Diba, M.; Fathi, M.; Kharaziha, M. Novel forsterite/polycaprolactone nanocomposite scaffold for tissue engineering applications. Mater. Lett. 2011, 65, 1931-1934. [CrossRef]

30. Augustine, R.; Malik, H.N.; Singhal, D.K.; Mukherjee, A.; Malakar, D.; Kalarikkal, N.; Thomas, S. Electrospun polycaprolactone/ $\mathrm{ZnO}$ nanocomposite membranes as biomaterials with antibacterial and cell adhesion properties. J. Polym. Res. 2014, $21,1-17$. [CrossRef] 
31. Barud, H.S.; Ribeiro, S.J.; Carone, C.; Ligabue, R.; Einloft, S.; Queiroz, P.; Borges, A.P.; Jahno, V. Optically transparent membrane based on bacterial cellulose/polycaprolactone. Polímeros 2013, 23, 135-142. [CrossRef]

32. Christensen, P.; Egerton, T.; Martins-Franchetti, S.; Jin, C.; White, J. Photodegradation of polycaprolactone/poly (vinyl chloride) blend. Polym. Degrad. Stab. 2008, 93, 305-309. [CrossRef]

33. Balu, R.; Kumar, T.; Ramalingam, M.; Ramakrishna, S. Electrospun Polycaprolactone/Poly (1,4-butylene adipate-copolycaprolactam) blends: Potential biodegradable scaffold for bone tissue regeneration. J. Biomater. Tissue Eng. 2011, 1, 30-39. [CrossRef]

34. Yahiaoui, F.; Benhacine, F.; Ferfera-Harrar, H.; Habi, A.; Hadj-Hamou, A.S.; Grohens, Y. Development of antimicrobial $\mathrm{PCL} /$ nanoclay nanocomposite films with enhanced mechanical and water vapor barrier properties for packaging applications. Polym. Bull. 2015, 72, 235-254. [CrossRef] 